Cadernos de Filosofia Alemã 4, PP. 65-79, 1998

\title{
A relação entre moral e direito em Kant*
}

\author{
Abrahão Costa Andrade**
}

\begin{abstract}
Resumo: O texto procura ser uma análise da introdução geral da Metafísica dos Costumes de Kant. Sua tarefa consiste em articular as relações entre ética e direito mostrando suas especificidades e as maneiras como se entrelaçam com os conceitos de obrigação, liberdade e legislação a partir dos pontos de vista da interioridade e da exterioridade.
\end{abstract}

Palavras-chave: moral - direito - ética - liberdade - autonomia

Expondo a filosofia kantiana do direito, Victor Delbos, em La philosophie pratique de Kant, não hesita em afirmar que a Metafísica dos costumes, longe de oferecer uma dedução sistemática e rigorosa dos primeiros princípios da doutrina do direito e da virtude, "não é mais que um esforço freqüentemente penoso e estéril de simples arrumação esquemática". Logo em seguida, acrescenta: "o pensamento aparece aí congelado nas definições e proposições outras vezes estabelecidas; ele não tem nem amplidão nem flexibilidade, nem sempre lucidez" (Delbos 3, p. 559). Articular, portanto, o problema das relações entre direito e moral no pensamento de Kant não é uma tarefa fácil. Não fossem as várias leituras que dele se fazem ${ }^{1}$, restariam ainda questões de ordem terminológica, que devem ser as primeiras a serem abordadas e, talvez, também as mais árduas. Para enfrentar a tarefa, analisaremos apenas alguns pontos da introdução à Metafísica dos costumes.

\footnotetext{
* Este texto é parte de um trabalho maior apresentado ao Prof. Dr. Ricardo Ribeiro Terra como resultado do aproveitamento de seu curso "Moralität und Sittlichkeit". Queremos agradecer a ele, por seus valiosos esclarecimentos em aula, e também a Ana Lúcia Mandacaru Lobo, Soraya Dib Abdoul-Nour, Maurício Keinert e Luís Nascimento, além de Anderson, Luciana e Nicolás, pelas oportunas sugestões de aprimoramento do texto e de sua correção.

** Mestrando no Departamento de Filosofia da FFLCH-USP e bolsista do CNPq.
} 
Nesse texto, dentre vários outros temas, Kant se refere marcadamente à física, e de modo a traçar com ela um paralelo. Kant mostra como funciona, na física, a relação entre a ciência e seus princípios para, em seguida, mostrar como tudo é diferente no caso da moral. O caso aqui é o do estabelecimento da universalidade, mas também do conflito, no homem, de suas duas dimensões, a sensível e a racional. Assim vemos como o texto, traçando o paralelo entre física e moral, conduz-se para o confronto entre o que no homem é sensível e de modo algum pode se relacionar com a moralidade, e o que nele é racional, de maneira a ressaltar também que o racional é o propriamente moral.

Uma ciência será universal, sabemos, quando também for necessária. A necessidade de um saber é assegurado mediante sua pertença a princípios puros a priori. Claro está, portanto, que a física possui os tais princípios. "É o que foi provado alhures", diz Kant. Mas, se por um lado, para ter um valor universal no sentido estrito, ela deve ser derivada de princípios a priori, por outro lado, "a física pode (pelo menos quando se trata de preservar suas proposições do erro) admitir mais de um princípio como universal sobre o testemunho da experiência" (Kant 6, p. 89). Isto não pode acontecer no caso das leis morais. Elas só valem "como lei na medida em que podem ser olhadas como fundadas a priori e como necessárias" (id., ibid.). Assim, num próximo passo, Kant procura mostrar como não funciona a moral, ou como ela funcionaria, se tomasse a física como exemplo.

Se lemos a Fundamentação, vemos que a pesquisa que busca um princípio universal para a moralidade não se move apenas pela sede de especulação mas também atende a um desejo de melhorar o homem e seus costumes. Quer dizer, a investigação científica da moralidade é, também ela, moral. Por isso Kant chega a afirmar que "os conceitos e os juízos que interessam a nosso ser, nossas ações e omissões não significam nada de moral, quando só contêm o que é possível saber pela experiência" (id., ibid.). Destarte, se não se busca este princípio universal a priori, independente da experiência, comete-se uma injustiça para com os homens (se bem que estes já o trazem consigo, embora não explicitado pela investigação filosófica), pois se os deixam expostos, diz Kant, aos mais grosseiros e perniciosos erros.

Ademais, se é seguido o exemplo da física e são procurados princípios empíricos para a moral - e este é o erro absoluto -, confunde-se moralidade e felicidade e, com isso, perde-se o sentido de qualquer busca posterior de princípios universais, pois só a experiência pode ensinar a quem só procura o gozo. Com efeito, se houvesse necessidade de buscar princípios na experiên- 
cia, se a doutrina da moral fosse também doutrina da felicidade, não haveria porque pedir apoio a princípios a priori, pois estes, ao contrário, mais atrapalhariam que contribuiriam com alguma coisa. Mas, num outro sentido, não é só esse o problema. Enquanto na física a experiência ainda pode oferecer princípios universais, na moral a coisa se passa de maneira totalmente diferente. O máximo que ela pode oferecer é generalidade.

Assim, se a doutrina da moral, por um lado, pretende apresentar-se como algo totalmente diferente da doutrina da felicidade e, por outro, com uma universalidade muito bem assegurada, ela não pode assentar-se senão em princípios a priori. Quer dizer, não deve falar às inclinações dos homens mas apenas àquilo que os faz livres e dotados de uma razão prática pura. Deste modo, argumenta Kant: "Se portanto um sistema a priori do conhecimento por simples conceito se chama metafísica, então uma filosofia prática, que tem por objeto não a natureza mas ao contrário a liberdade do arbítrio, pressuporá e exigirá uma metafísica dos costumes: possuir uma tal metafísica é já um dever e todo homem a possui nele mesmo, se bem que confusamente a maior parte do tempo. Como, com efeito, poderia ele crer possuir nele mesmo uma legislação universal sem princípios a priori?” (Kant 6, p. 91).

Uma leitura apressada poderia ver em todas essas afirmações uma excessiva aversão à experiência. Talvez esteja aí a razão de ser daquela acusação segundo a qual a ética kantiana não passa de um formalismo. Acusação injusta? Não vem ao caso agora avaliá-la ${ }^{2}$; o certo é que, se por um lado é necessário, para pensar com precisão, que a ética se construa segundo princípios $a$ priori, por outro lado em momento algum do texto Kant perde a referência à física; tanto é assim que construirá uma metafísica dos costumes como pendant da metafísica da natureza. Mais ainda: uma vez asseguradas a pureza e a independência de seus princípios, nada impede - muito pelo contrário - que estes venham a ser aplicados na experiência ${ }^{3}$. Por isso, nosso Autor pode adiantar: "Tudo mesmo que há numa metafísica da natureza, os princípios (Prinzipien) da aplicação dos princípios (Grundsätze) supremos e universais da natureza em geral, tudo mesmo deve aí estar numa metafísica dos costumes e nós deveremos frequientemente tomar como objeto a natureza particular do homem, que não é conhecida senão pela experiência, a fim de aí indicar as consequiências destes princípios morais universais, sem que por isso a pureza destes princípios seja diminuída, nem sua origem a priori tornada duvidosa. - O que significa exatamente que uma metafísica dos costumes não pode ser fundada sobre a antropologia, se bem que ela possa aí ser aplicada" (id., ibid.). 
O prosseguimento do texto deixa muito claro o lugar da antropologia moral como parte empírica da filosofia prática ${ }^{4}$ : ela não pode se misturar à parte pura nem precedê-la, mas recebe a justa tarefa de fazer valer na experiência os princípios desta.

Posto assim o assunto, todavia, surge inevitavelmente no espírito do leitor a clássica questão da passagem do universal ao particular, com a qual Kant está em seu pensamento o tempo todo às voltas: como passar dos princípios a priori às máximas concretas das ações? Ora, justamente no ponto onde surge esta indagação Kant passa a falar, no texto, "sobre a divisão superior da filosofia (...) em filosofia teórica e prática” (Kant 6, p. 92). Ele nos remete, com isso, à Crítica do Juízo. Neste texto, à divisão superior da filosofia corresponde a divisão das faculdades superiores da mente; nele ainda, uma das questões fundamentais, senão a principal, é a questão da passagem entre natureza e liberdade; mais ainda: este mesmo texto deixa muito clara a diferença entre juízos técnico-práticos e moral-práticos. Embora sem que precisemos visitar a terceira Crítica, a continuação da análise nos convida a traçar, no mesmo texto ora visado, a relação das faculdades da alma com as leis morais.

A primeira impressão que a leitura deste ponto - a relação entre as faculdades da mente e as leis morais no sentido de se vislumbrar uma passagem da liberdade para a natureza - deixa ressaltar é a presença de uma série de termos e noções comuns ao kantismo; e sua primeira dificuldade é justamente esta: exige do leitor para com elas um intimidade já adquirida, o que às vezes nem sempre é o caso. Uma segunda impressão (mas essa exige um pouco mais de atenção) é a de que, neste ponto, Kant produz, no rumo de sua argumentação, um deslocamento para o campo concreto da existência, para com isso voltar ao ponto inicial enriquecido com pelo menos duas conquistas: um conceito de "prática" e dois conceitos, assim como dois usos, da palavra "liberdade".

Kant começa este ponto dando uma definição da faculdade de desejar. Ela é a faculdade "de ser por suas representações causa dos objetos dessas representações" (id., ibid., p. 85). E imediatamente nomeia o âmbito - a vida - em que se estabelece esta força capaz de produzir seus próprios objetos: "A faculdade de um ser de agir segundo suas representações se chama a vida" (id., ibid.). Dois motivos parecem justificar este começo: vai-se falar das relações entre desejo e sentimento, e os sentimentos, como as ações, são uma dimensão da vida. 
Por sentimento, Kant entende a receptividade (Empfänglichkeit) do prazer e do desprazer. As relações entre desejo e sentimento podem ser de dois tipos, segundo o prazer ou o desprazer, tomados ao objeto do desejo, possam ser considerados como causa do desejo ou como efeito dele. Mas, se por um lado o desejo ou a aversão está sempre ligado a um sentimento de prazer ou desprazer, por outro lado pode haver casos em que se dão os sentimentos sem nenhuma ligação com o desejo. Assim, os sentimentos podem ser encarados sob três aspectos: como causa do desejo, como efeito do desejo e separadamente (mas neste último caso, não para serem explicados pela razão a partir deles mesmos: apenas para "indicar quais consequiências eles têm em certas relações para os fazer conhecer quanto ao uso" (Kant 6,p. 86). Para voltarmos nossa atenção para este último caso, nossa tarefa consiste em tentar entender a especificidade do sentimento.

Seja como causa, seja como efeito de um desejo, os sentimentos de prazer ou desprazer estão, nestes casos, ligados a um objeto. A especificidade do terceiro caso, porém, é justamente não se referir a objeto algum e, por isso, caracterizar-se como das blosse Subjektive (o mero subjetivo); conseqüentemente, o que é próprio dele é não servir para nenhum conhecimento, pois o conhecimento é uma representação que sempre está ligada a um objeto. Sendo assim, Kant desenvolve: "Pode-se em geral definir a sensibilidade pelo subjetivo (das Subjektive) de nossas representações; com efeito, o entendimento relaciona antes de tudo representações a um objeto, isto é, que ele não pensa uma coisa senão por sua mediação. Mas o subjetivo de nossas representações pode, ou bem ser tal que possa também ser relacionado a um objeto em vista de seu conhecimento (segundo a forma ou segundo a matéria, e no primeiro caso ela se nomeia "intuição pura", mas no segundo "sensação"); e então a sensibilidade como sendo a capacidade de ter representações pensadas é o sentido. Ou bem o subjetivo da representação não pode absolutamente tornar-se um elemento de conhecimento, porque só contém simplesmente sua relação com o sujeito e nada que possa servir ao conhecimento do objeto; e neste caso a capacidade da representação é dita sentimento" (id., ibid., p. 87).

O subjetivo, como se vê, pode ser compreendido de duas maneiras. Quando se trata de representações ligadas ao entendimento como substrato material-formal para o seu funcionamento na produção do conhecimento, falase, segundo a forma, de intuição pura, e segundo a matéria, de sensação, e 
assim, ele é um elemento de conhecimento, ou seja a sensibilidade. Quando, porém, escapa destas determinações, o subjetivo é uma capacidade de representação desinteressada; a esta capacidade chamamos sentimento de prazer ou desprazer. Isentos de implicações cognoscitivas, dele só podemos saber algo acerca de seu uso.

O sentimento de prazer, quando não está ligado ao desejo seja como sua causa ou seu efeito, é chamado prazer contemplativo ou satisfação inativa. Trata-se de um prazer não tomado "à existência do objeto da representação mas que se liga apenas à representação" (Kant 6, p. 86). A este sentimento específico Kant chama gosto. Note-se que a faculdade de desejar, sendo por suas representações a causa dos objetos destas, não se satisfaz apenas com elas mas se apressa em produzir seus objetos. Ela é assim essencialmente ativa. $\mathrm{O}$ sentimento, porém, enquanto receptividade, apraz-se em apenas ter acesso à representação sem chegar nem a produzir nem a aproximar-se do objeto. Ele é puramente contemplativo. Ora, uma filosofia prática, como o nome já o indica, é uma filosofia da ação e, portanto, a questão do gosto jamais será uma sua questão a não ser episodicamente.

Episodicamente, porém, o prazer pode acompanhar o desejo de duas maneiras, já enunciadas: como sua causa ou seu efeito. "Pode-se chamar prazer prático o que está necessariamente ligado com o desejo (do objeto cuja representação afeta o sentimento)" (id., ibid.). Quando isso acontece, diz-se que o sentimento está ligado a um interesse. $O$ interesse provindo da ligação do sentimento com o desejo quando aquele é causa deste é chamado interesse da inclinação; quando ao contrário aquele é apenas o efeito, temos o interesse da razão. Observemos em primeiro lugar o caso quando o sentimento afeta o desejo como sua causa: "Quanto ao interesse prático a determinação da faculdade de desejar, que o prazer deve necessariamente preceder como causa, chamar-se-á no sentido estrito desejo (Begierde) enquanto os desejos habituais serão ditos inclinações (Neigung). E porque a ligação do prazer com a faculdade de desejar, na medida em que esta ligação pode ser julgada como válida pelo entendimento seguindo uma regra universal (mas em todo o caso somente para o sujeito), chama-se interesse, o prazer prático é neste caso um interesse da inclinação" (id., ibid.).

Entretanto, se o prazer simplesmente segue uma determinação da faculdade de desejar anterior a ele, ele deixa de ser sensível, e o desejo que determina esta situação já não pode ser chamado inclinação a não ser por condescendência ao uso da língua. Mesmo assim seria uma inclinação livre dos sen- 
tidos (sinnenfreie Neigung, propensio intellectualis). Ele passa a ser fundado nos princípios puros da razão. É um prazer intelectual - "e o interesse tomado ao objeto deve ser um interesse da razão" (Kant 6, p. 86). Nestes termos, a faculdade de desejar, pode-se dizer, é autônoma, não se confunde nem com a inclinação sensível nem com a concupiscência (ou a cobiça), pois esta é sempre uma determinação sensível. Desta maneira, explicita Kant: "A faculdadede-desejar seguindo os conceitos, na medida em que seu princípio de determinação à ação se acha nela mesma e não no objeto, é dita a faculdade de fazer ou de não fazer segundo seu capricho (nach Belieben zu tun oder zu lassen). $\mathrm{Na}$ medida em que esta faculdade está ligada à consciência da faculdade de agir para produzir o objeto, ela se chama arbítrio (Willkür), mas se ela não lhe está ligada seu ato será dito um voto. A faculdade de desejar, que possui o seu princípio de determinação interior na razão, de modo que o assentimento (das Belieben) se acha ele mesmo na razão do sujeito, chama-se vontade (Wille). A vontade é portanto faculdade de desejar considerada não tanto com relação à ação (como o arbítrio) mas pela relação com o princípio de determinação do arbítrio à ação. Ela não é portanto, para quem a olha estritamente, princípio de determinação, mas na medida em que pode determinar o arbítrio, ela é a própria razão prática" (id., ibid., p. 87).

Vimos acima, com efeito, que o homem possui uma dupla dimensão: tanto é sensível quanto racional. Aqui, como de resto em outros textos, Kant adianta o seguinte: apenas quando age conforme a razão é que o homem é propriamente humano e, mais, a razão pura, à medida em que determina a faculdade de desejar, é ela mesma prática. Com isto, anunciam-se os dois conceitos de liberdade: "É na medida em que a razão pode em geral determinar a faculdade de desejar que o arbitrio, e mesmo o simples voto, pode ser compreendido sob a vontade. $\mathrm{O}$ arbítrio que pode ser determinado pela razão pura se chama o livre arbítrio (frei Willkür). O arbítrio que só é determinado pela inclinação (móbil sensível, stimulus) será um arbítrio animal (arbitium brutum). O arbítrio humano ao contrário é tal que pode ser sem dúvida afetado pelos móbeis sensíveis, mas por eles não pode ser determinado; tomado nele mesmo (sem hábito adquirido da razão), ele não é portanto puro; ele pode contudo ser determinado à ação por uma vontade pura" (id., ibid.).

A liberdade, diz Kant, pode ser definida sob duas formas: uma negativa e outra positiva. A primeira forma, a negativa, define-se pela sua independência, quanto à determinação do arbítrio, de afetações sensíveis, isto é, liberdade é a capacidade de não se deixar levar pelos impulsos da sensibilidade. A 
segunda forma, a positiva, corresponde à definição de autonomia: "o conceito positivo da liberdade é a faculdade da razão pura de ser por ela mesma prática" (Kant 6, p. 88). Porém, como isto é possível?

Isto é possível, responde Kant, somente "pela submissão das máximas de toda ação à condição de poder servir de lei universal" (id., ibid.). Para compreender melhor esta resposta, seria interessante acompanhar um pouco a leitura de Bernard Rousset, em seu La doctrine kantienne de l'objetivité, pois a transformação da máxima em lei ou a aplicação da lei moral à máxima da ação é uma questão de objetividade. Com efeito, a moralidade não é mais que uma consequiência da autonomia e "a filosofia prática de Kant não é imediatamente uma moral do dever, ela só se o torna porque é antes uma doutrina da objetividade e da autonomia" (Rousset 8,p. 515). Porque o homem é, além de racional, também sensível, nem sempre a máxima de suas ações, que são sempre subjetivas, correspondem à objetividade da lei moral. Por isso, esta objetividade se exprime por meio do imperativo categórico que proíbe ou ordena universalmente, levando o homem a lançar-se para além de si mesmo e realizar-se como ser racional, isto é, livre.

A liberdade, além de possuir este duplo conceito, negativo e positivo, possui também dois usos bastante específicos, e nós os apreendemos segundo as noções de exterioridade e interioridade. Quando as leis da liberdade - que à diferença das leis da natureza são chamadas morais - "suportam apenas ações exteriores e sua legalidade, elas são ditas jurídicas" (Kant 6, p. 88). Quando, ao contrário, enquanto leis, exigem "os princípios de determinação das ações, elas são então éticas" (id., ibid.). Assim, "o acordo com as leis jurídicas é a legalidade das ações, enquanto o acordo com as leis morais é a moralidade" (id., ibid.). O importante a observar aqui é a oscilação, num mesmo parágrafo, entre os conceitos de "moral" e "ética". Kant toma o termo moral como genérico, do qual fazem parte a ética e o direito. Logo em seguida, porém, diz: "o acordo com as leis morais" etc., e não, como seria de esperar, "o acordo com as leis éticas" (Terra 9, p. 77).

As relações entre o acordo com as leis éticas - a moralidade - e o acordo com as leis jurídicas - a legalidade - apresentam-se sob a égide das noções de exterioridade e interioridade. Nestas relações, três elementos devem ser levados em conta: a obrigação, a liberdade e a legislação. Em Eine Vorlesung über Ethik, citado por Alexis Philonenko (nota 4), Kant acrescenta às noções de exterior e interior as de perfeição e imperfeição, no sentido bem próprio destes termos - o de completude e incompletude. Introduz ele aí a noção de 
coerção (Zwang), dizendo que as ações exteriores são perfeitas, ao contrário das interiores, porque além do elemento moral que possa nela estar contido há o constrangimento externo, de modo a ação ter de se realizar necessariamente. "As obrigações interiores são obrigações imperfeitas" (...) "mas as obrigações externas são perfeitas pois à obrigação moral se acrescenta ainda, além disso, o constrangimento externo" (Philonenko, em: Kant 6, p. 35). Neste sentido, perfeita mesmo só a ação jurídica. Por outro lado, o texto da Metaphysik fala aqui não de obrigação interna e externa, mas de "liberdade". A liberdade da lei jurídica só pode ser externa, enquanto a da moral tanto pode ser externa quanto interna, de modo a podermos dizer ser esta última a realmente perfeita. "A liberdade com a qual se relacionam as leis jurídicas só pode ser a liberdade em seu uso exterior, mas a com a qual se relacionam as leis morais é a liberdade no uso tanto externo quanto interno do arbítrio, porquanto está determinada por leis racionais" (id., ibid.). Quanto à legislação, "a legislação ética, diz ele um pouco mais adiante, é a que não poderia ser exterior, a legislação jurídica é a que pode ser também exterior" (id., ibid., p. 94). Temos assim um quadro que se traduz na seguinte forma: a obrigação ética só pode ser interna, a jurídica tanto interna quanto externa; a liberdade jurídica só pode ser externa, a ética tanto externa quanto interna; a legislação ética só pode ser interna, a jurídica tanto interna quanto externa. Compreendemos muito bem porque a obrigação ética só pode ser interna: não há nada fora dela que a mova, nenhum móbil exterior; compreendemos, ainda, porque a legislação ética só pode ser interna: suas leis são elaboradas pela própria disposição moral do sujeito, a autonomia. Resta, contudo, compreender como a liberdade ética pode se manifestar interna e externamente.

Antes, todavia, insistamos um pouco mais nesta distinção entre interno e externo. Kant termina uma seção de seu texto fazendo uma curiosa comparação entre estas considerações da filosofia prática e a filosofia teórica: "É assim que se diz na filosofia teórica: não há no espaço senão os objetos do sentido externo, mas todos os objetos estão no sentido interno, tanto os do sentido externo quanto os do sentido interno. Mesmo que se possa considerar a liberdade no seu uso seja externo, seja interno do arbítrio, mesmo suas leis, como puras leis práticas racionais para o livre-arbítrio em geral devem nisto ser ao mesmo tempo os princípios internos de determinação, ainda que não sejam sempre considerados sob esta relação" (id., ibid., p. 88).

A nos determos na última frase supracitada - "devem nisto ser etc..."-, vemos como o problema da liberdade se resolve na questão do dever. A liber- 
dade é considerada em sua dupla determinação (interna e externa) porque ela não pertence ao campo do ser simplesmente mas ao campo do dever ser. É o dever que garante sua objetividade e oferece-lhe a possibilidade de ser tanto interna quanto externa ao mesmo tempo. É pelo dever que a liberdade se realiza.

Para fazer compreender a relação entre liberdade e dever, Kant lembra alguns passos da Crítica da razão pura (afirmando a impossibilidade de se ter da liberdade um conhecimento teórico adequado), assim como alguns passos da Crítica da razão prática (reafirmando a única maneira pela qual se pode ter acesso a ela; como sabemos, no uso prático da razão). A filosofia teórica se ocupa com conceitos de objetos da experiência. A experiência não pode oferecer nenhum objeto correspondente ao conceito de liberdade. Assim, "o conceito da liberdade é um puro conceito da razão", uma idéia, "que precisamente segundo esta razão é para a filosofia teórica transcendente" (Kant 6, p. 95), isto é, extravasa o campo da experiência possível. Vê-se, portanto, que se o campo do conhecimento se limita ao princípios constitutivos do entendimento, como à faculdade de julgar determinante (no caso em que é dada a regra e, com ela, procura-se subsumir os particulares), a liberdade deve localizar-se, para adquirir uma primeira validade - o seu conceito negativo - nos princípios regulativos da razão, o único que lhe é realmente válido, e que consiste em pensar a natureza em vista de um sistema, apenas segundo uma idéia. Neste momento, não sabemos ainda o que é a liberdade, sabemos apenas o que ela não é. A liberdade no sentido negativo se define como independência das inclinações sensíveis. Somente quando se prova os princípios práticos da razão e se estabelece a legitimidade de seu uso prático, ocorrendo a necessidade de se experimentar um novo conceito de causalidade não natural, somente aí a liberdade surge como causalidade da razão pura, determinando o arbítrio independente de toda condição sensível e atestando em nós "uma vontade pura, na qual os conceitos e as leis éticas têm sua origem" (id., ibid.). Compreendemos, assim, como a idéia de liberdade está ligada à idéia de lei ética. As leis éticas são o produto da autonomia, e esta é o conceito positivo de liberdade.

Surge aqui a oportunidade de relacionar ética e direito. Mas desta vez mostrando a sua afinidade principal: a moral só pode subsistir no conceito de liberdade como autonomia, e esta se manifesta segundo leis expressas em forma de imperativos de comando ou interdição ${ }^{5}$. Como ética e direito estão contidos no conceito de moral, é preciso concluir que ambos se efetuam sob o conceito de liberdade como autonomia, pois esta é o princípio supremo da 
doutrina dos costumes, que os engloba (Terra 9, p. 80). Neste contexto, o que vai diferenciá-los é apenas o móbil da ação.

Dito assim, é fácil perceber um erro de interpretação de um comentador de Kant: Noberto Bobbio. Em seu Direito e estado no pensamento de Kant, este autor lembra que, aos imperativos propriamente éticos Kant chama "categóricos", ou seja, incondicionados. Há, contudo, uma outra espécie de imperativos e são chamados, por se efetuarem condicionadamente, "hipotéticos". Os imperativos hipotéticos podem ser, como se sabe, técnicos ou de prudência (Aubenque 1,p. 152). Os técnicos são imperativos de habilidades; os de prudência, imperativos de conformidade. Uma vez que da ação de direito não se exige que se realize por amor incondicional ao dever mas apenas exteriormente conforme ao dever, Bobbio faz pensar que haveria razão em identificar os imperativos de prudência como apropriados à legislação jurídica. Neste sentido, elabora um outro critério para distinguir ética e direito, quanto a cada uma de suas legislações (Bobbio 2, p. 62): da legislação ética, poder-se-ia dizer que se baseia na autonomia; da jurídica, na heteronomia. Contudo, Kant, nesta seção analisada, e como o próprio Bobbio, inadvertidamente, lembra, não utiliza estes termos. O que ele diz é que, podendo haver dois tipos de legislação, um possui a lei "que representa objetivamente como necessária a ação a realizar, isto é, que faz desta ação um dever" (Kant 6, p. 92); o outro possui um móbil "que relaciona subjetivamente à representação da lei a determinação do arbítrio desta ação" (id., ibid., p. 93), isto é, que faz a ação depender de fatores simplesmente exteriores. O dever é apenas um motivo para se chegar a algo desejado anterior a ele. A diferença é que, para a primeira, o móbil da ação é o dever mesmo - a ação se efetua realizando o dever - e isto é tudo; para a segunda, ao contrário, o sujeito age de tal maneira a não contrariar o dever mas tendo em vista outros fins que não o próprio dever. A lei que domina o primeiro caso faz parte da legislação ética; a que domina o segundo faz parte da legislação jurídica. Mas o que está em jogo aqui é apenas o móbil; ambas as legislações permanecem sob o conceito de autonomia (Rohden 7, p. 124), pois a elaboração das leis só é concebível sob este conceito. Kant, por sua vez, desenvolve: "Cada legislação, por consequiência, (...) pode portanto ser diferente no que concerne ao móbil. A legislação que faz de uma ação um dever e ao mesmo tempo deste dever um móbil, é uma legislação ética. De contrapartida, a legislação que não integra o móbil à lei e que por conseguinte admite um outro móbil que não a Idéia do próprio dever é jurídica (Kant 6, p. 93). 
Nosso Autor observa, a propósito desta última, que é fácil reconhecer de que princípios ela retira a determinação de seu arbítrio: de princípios patológicos, isto é, de inclinações e aversões decorrentes de afetações sensíveis. Por isso chamará de legalidade (Gesetzmässigkeit) a simples conformidade (ou não conformidade) com a lei, "abstração feita dos móbeis desta", enquanto "a conformidade na qual a Idéia do dever segundo a lei é ao mesmo tempo o móbil da ação" (Kant 6,p. 93) será chamada moralidade. Mas esta distinção é apenas subjetiva, e diz respeito ao móbil da ação. Objetivamente, quanto à elaboração da lei, moralidade e legalidade são afins. "Por isso, diz Ribeiro Terra em seu já citado livro, não se pode tomar como correlatos os pares mo$\mathrm{ral} /$ direito e moralidade/legalidade. Uma leitura que os identificasse levaria a uma separação entre direito e ética sem apontar para os elementos comuns" (Terra 9, p. 77). Antes disso, contudo, Kant precisa mais a diferença: "Os deveres que decorrem da legislação jurídica não podem ser senão exteriores, pois esta legislação não exige que a Idéia deste dever que é interior seja por ela mesma princípio de determinação do arbítrio do sujeito agente e, como ele tem necessidade de móbeis apropriados às leis, ela não pode lhe relacionar a não ser móbeis exteriores. A legislação moral, ao contrário, faz também das ações interiores os deveres sem excluir as ações exteriores e se aplica a tudo que é dever em geral (Kant 6, p. 93).

Colocados assim os termos, voltamos a falar da relação entre interioridade e exterioridade. Vemos então Kant afirmar que a legislação ética, porque liga a lei ao móbil interno da ação (a idéia do dever) não poderia exercer nenhuma influência sobre a legislação exterior e, ainda que os deveres da legislação exterior não lhe possam ser de modo algum adversos, não poderia ser ela mesma exterior. Quer dizer, as ações realizadas conforme o direito, ainda que não sejam éticas, e elas não o são sempre, não podem ser contrárias à ética. Isto porque ambas, do ponto de vista da objetividade, estão ligadas ao conceito de autonomia. A autonomia pode ser considerada num sentido estrito e num sentido amplo. No primeiro sentido, quando está em jogo o imperativo categórico, ela se relaciona com o direito na medida em que este imperativo é o princípio supremo da doutrina dos costumes; mas "a autonomia poderá ser pensada em sentido amplo, como exigência de participação de todos na legislação, não levando em conta o móbil" (Terra 9, pp. 90-91). "Por isso explicita Kant -, só se pode ver que todos os deveres, unicamente porque são deveres, pertencem à ética; mas sua legislação não está contida sempre por esta razão na ética, mas ao contrário muitos dentre eles lhe são estranhos. É 
assim que a ética comanda que num contrato eu pague a promessa que eu fiz, ainda que a outra parte não possa me constranger a isso; entretanto ela admite a lei (pacta sunt servanda) e o dever que lhe corresponde como saídos da doutrina do direito" (Kant 6, p. 94).

A diferença, portanto, entre a doutrina do direito e a ética não está nos deveres que elas podem ou não prescrever mas no tipo de legislação que as comanda, de acordo com a interioridade (quando nada mais se pede senão a boa vontade e intenção de quem age segundo a idéia do dever) ou com a exterioridade (quando nem isso é pedido e a ação se efetiva apenas quer por ordem e constrangimento de outrem que não o agente, quer porque o agente nutre interesse por outros fins que não o respeito pela lei moral). Assim, se se sustenta uma promessa apenas porque com isso alcançar-se-á algo a mais, está-se apenas no âmbito das exigências da legislação jurídica; se, ao contrário, age-se de tal modo que a idéia do dever é o móbil da ação, a legislação aí exigida é a ética. Mas, na medida em que toda obrigação deve fundar-se na razão prática (Terra 9, p. 90), ética e direito se comunicam sob o conceito de autonomia, que é o princípio desta razão.

\footnotetext{
Abstract: The text's main goal is to be a general introduction to Kant's Metaphysics of morals. Its task is to articulate the relationship between ethics and the principles of right, understand its specificities and the manner in which they imbricate themselves with the concepts of obligation, freedom and legislation from inner and external perspectives.
}

Key-words: moral - right - ethics - freedom - autonomy 


\section{Notas}

1. Em A política tensa, Ricardo R. Terra apresenta três leituras diferentes, duas das quais centrando-se na relação entre moral e direito, e uma terceira na questão da liberdade. Representativo da primeira seria G. Solari, "que está preocupado com a independência do direito em relação à moral" (Terra 9, p. 83); uma segunda interpretação é aquela de Kurt Lisser, que procura submeter o direito à ética na medida em que ambos pertencem à doutrina dos costumes. Terra chama a atenção para o fato de que ambas interpretações se sustentam à medida em que negligenciam certos aspectos da filosofia kantiana. A terceira leitura é a de Noberto Bobbio, que dá ênfase nos dois conceitos de liberdade situados na base da distinção entre direito e moral. "A primeira concepção é a liberal, defendida por Montesquieu, e a segunda, a democrática, defendida por Rousseau" (id., ibid., p. 86). O autor lembra ainda que, curiosamente, ambas concepções estão em Kant, sendo a democrática "a definição explícita e a liberal, aquela que orientaria a sua teoria", concordando com Bobbio no fato de que em Kant "os elementos liberais são inegáveis" (id., ibid., p. 87). Na avaliação geral, porém, o autor conduz a análise de modo a fazer valer o pensamento de Kant ele mesmo, ainda que carregado de tensões.

2. Fala-se do formalismo da ética kantiana pelo menos desde Hegel. Para uma exposição assim como uma crítica da crítica hegeliana da ética de Kant, veja-se Guéroult 4. Segundo Bernard Rousset, que lê toda a obra de Kant sob o viés da doutrina da objetividade, é verdade que a lei moral é formal, pois ela é uma relação "e toda relação é uma simples forma" (Rousset 8, p. 514). De resto, como consequência da reviravolta corpenicana, "o formalismo do a priori puro é portanto um método de construção" (id., ibid.). Embora não se trate de um texto de história da filosofia, seria bom conferir o texto de Habermas (Habermas 5), em que se discute, dentre outros pontos, o problema do formalismo na ética contemporânea.

3. Cf. Zingano 10, p. 189 e ss: "Isto significa um avanço conceitual sobre o concreto, um alargamento do conceito em direção do outro que quer cingir".

4. Alexis Philonenko, em nota à introdução de sua edição da Métaphysique des moeurs, cita uma passagem de Eine Vorlesung über Ethik, de Kant, em que nosso Autor, compreendendo as obrigações morais como obrigações apenas interiores, concebe uma ação perfeita quando se realiza tanto interior como exteriormente. "As obrigações interiores são obrigações imperfeitas, porque não podemos neste caso ser forçados; as obrigações externas são perfeitas pois à obrigação moral acrescenta-se ainda, além disso, o constrangimento externo" (Kant 6, p. 35). Ao que Philonenko acrescenta: "Este ponto de vista, unificando antes que separando direito e moral, é ainda o dos kantianos em 1795-96" (id., ibid.).

5. "O imperativo é uma regra prática, pela qual uma ação nela mesma contingente é tornada necessária” (Kant 6, p. 96). 


\section{Referências Bibliográficas}

1. AUBENQUE, P. “La prudence chez Kant”. Em: La prudence chez Aristote. Paris, PUF, 1967.

2. BOBBIO, Noberto. Direito e Estado no pensamento de Emmanuel Kant. Brasília, UnB, 1984.

3. DELBOS, V. La philosophie pratique de Kant. Paris, PUF, 1969

4. GUÉROULT, M. “Les 'déplacements'(Verstellungen) de la conscience moral kantienne selon Hegel”. Em: Hommage a Jean Hippolite. Paris, PUF, 1971.

5. HABERMAS, J. "Les objections de Hegel à Kant valent-elles également pour l'éthique de la discussion?". Em: De l'éthique de la discussion. Paris, Cerf, 1992.

6. KANT, I. Métaphysique des moeurs, Doctrine du droit. Paris, Vrin, 1979.

7. ROHDEN, V. "Razão prática e direito”. Em: Racionalidade e ação. Org. Valério Rohden. Porto Alegre, Editora da Universidade, 1992.

8. ROUSSET, B. La doctrine kantienne de l'objetivité. Paris, Vrin, 1967.

9. TERRA, R. R. A política tensa. São Paulo, Iluminuras/Fapesp, 1995.

10.ZINGANO, M. A. Razão e história em Kant. São Paulo, Brasiliense, 1989. 